\title{
Analysis of Ground Magnetic data by Logarithmic curves in parts of Federal University of Petroleum Resources Effurun, Delta State
}

\author{
Deameta .T. Kess ${ }^{1}$, Williams Ofuyah ${ }^{1}$, Eze Stanley ${ }^{1,2}$, Nnorom .S. Lotanna ${ }^{1}$, Abolarin .O. Macpaul ${ }^{3}$ \\ ${ }^{1}$ Department of Earth Sciences, Federal University of Petroleum Resources Effurun, Delta State. \\ ${ }^{2}$ Department of Marine Geology, Nigeria Maritime University, Okerenkoko, Delta State. \\ ${ }^{3}$ Department of Petroleum Engineering and Geosciences, Petroleum Training Institute, Effurun, Nigeria. \\ *Correspondence: uchechukwueze2014@gmail.com
}

\begin{abstract}
The aim of this study is to introduce a novel technique used for mapping subsurface structures in a sedimentary environment using the magnetic exploration method. Vertical component of the Earth's magnetic field and its derivative taken at $1.4 \mathrm{~m}$ above the measured vertical field were acquired in parts of Federal University of Petroleum Resources Effurun, Delta State, using an AMC-6 high precision magnetometer. The datasets were analysed by logarithmic curves. Six magnetic profiles were established in the area five in the strike direction and one along dip lines. A total of ten stations were sampled along each profile with an interstation spacing of $2 \mathrm{~m}$. This was followed by the conversion of the vertical field into geomagnetic attributes after the necessary corrections were applied to the data. The data was plotted in logarithm to base two to show the pattern of distribution of the data since the normal plot does not show the distribution clearly as datasets show feeble changes and the readings were close in amplitude values. When datasets are close we check for skewness of the data. The result obtained showed regions of high data concentration which corresponds to a peak (highest point) on the logarithmic plot and indicates anomalous zones of interest within the subsurface. Map of vertical components of the area showed steep slope (closely spaced contours) observed towards the North-Eastern part of the area while at the central part, anticlinal structures which decreases gentle outwardly were observed and a gentle slope which decreases towards west was also observed. The result indicates the presence of anticlinal structures in the subsurface which have valley-like depressions between them.
\end{abstract}

Keywords: Magnetic field, Magnetic derivatives, Vertical component, Logrithmic curves, nanotesla (nT), Sedimentary environment,

\section{Introduction}

The ambiguity and non-uniqueness in interpretation of magnetic data acquired in sedimentary environments cannot be over emphasized due to the feeble changes in magnetic response in sedimentary environments as most sedimentary materials are paramagnetic and diamagnetic in nature. Magnetic prospecting looks for variations in the magnetic field caused by changes in subsurface geological structure or by differences in the magnetic properties of near-surface rocks ${ }^{[1]}$. The inherent magnetism of rocks is called the magnetic susceptibility of which sedimentary rocks generally have a very low magnetic susceptibility compared to igneous or metamorphic rocks (in a basement terrain) which tend to have a much higher magnetite content (a common magnetic mineral). Since sedimentary rocks have very low magnetic susceptibility, magnetic data acquired in sedimentary environment shows feeble or weak response in amplitude of magnetic anomalies. Therefore, interpretation of such data is done by plotting the data with a logarithmic scale rather than the conventional plot. The data values are spread out better with the logarithmic scale to form a pattern or trend in variation in magnetic response ${ }_{[2]}$. The use of logarithmic curves for analysis of magnetic data was discussed by Hutchison (1958) "for plotting the magnetic anomaly of a magnetized dyke model and two other closely related models which provide master curves that can be used for a large variety of two-dimensional anomalies".

There are two main reasons why we use logarithmic scales in charts and graphs, first is to respond to skewness towards large values i:e, cases in which one or a few points are much larger than the bulk data, and secondly is to show percentage change or multiplicative factors.

The magnetic method is used to investigate subsurface geology on the basis of the anomalies in the earth's magnetic field resulting from the magnetic properties of the underlying rocks ${ }^{[3]}$. The shape, dimensions, and amplitude of the anomalies is a function of the orientation, geometry, size, depth, and magnetic susceptibility of the underlying

[Received 03 May 2020; Accepted 29 Oct 2020; Published (online) 31 Dec 2020] Publisher's Note: RCLSS stays neutral regard to jurisdictional claims published maps (c) (1) 


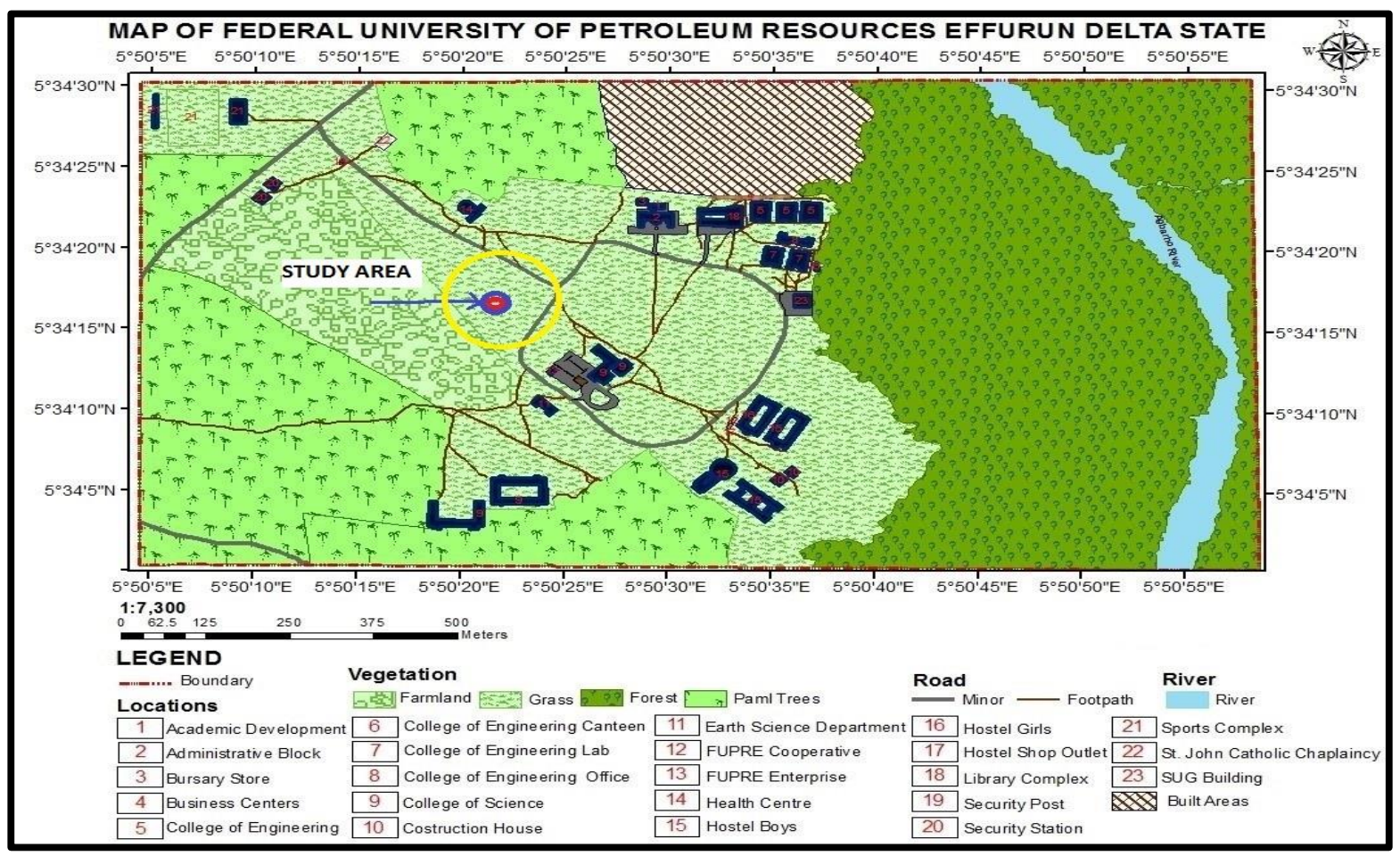

Figure 1: Location map of study area, Federal University of petroleum resources Effurun, (FUPRE, South-South Nig).

body as well as the intensity and inclination of the earth's magnetic field in the surveyed area.

Previous studies on magnetic survey within sedimentary basins used aeromagnetic data (airborne survey) over Naraguta sheets and its environs to delineate structutral discontinuities within the basin ${ }^{[4]}$. Most reports on magnetic method within sedimentary basins were inferred from interpretation of aeromagnetic data and satellite imageries (Landsat data) which are airborne surveys. Landsat imagery has a spatial resolution of $30 \times 30 \mathrm{~m}$ and 11 spectral bands covering the visible and thermal region of the electromagnetic spectrum $_{[5]}$. This makes airborne surveys faster in acquisition and have a wide areal coverage, but are rather expensive.

The aim of this study is to demonstrate the use of logarithmic plot (LOG-LOG plot to base two) to analyse ground magnetic data acquired using AMC-6 high precision magnetometer (fluxgate-type magnetometer) in parts of Federal University of Petroleum Resources Effurun (FUPRE), located in Warri, Delta State, which lies within the Niger Delta sedimentary environment, to check for skewness in data distribution and trend in magnetic anomaly which gives a picture of the subsurface geology of the area.

\section{Literature Review of the study area}

The study area, Federal University of Petroleum Resources Effurun (FUPRE) campus is located in Warri Delta State. Warri shares boundaries with Udu and Uvwie Local government areas of Delta State. Warri serves as the economic nerve of the State. Geographically, Warri and Effurun are located between latitudes $05^{\circ} 30^{\prime} \mathrm{N}$ to $05^{\circ} 35^{\prime} \mathrm{N}$ and longitudes $005^{\circ} 29^{\prime} \mathrm{E}$ to $005^{\circ} 48^{\prime} \mathrm{E}$. The climate of the area is the tropical equatorial type dominated by two seasons, a long wet season (April to October) and a short dry season (November to March), in response to the interplay between the southwest and the northeast trade winds that blows over Nigeria. Annual rainfall is usually in excess of $3000 \mathrm{~mm}{ }^{[6]}$. The Geology of Effurun region is seen to be same as the Niger Delta, comprising of three lithological units (stratigraphy) known as: The Akata Formation which is the oldest is overlain by Agbada Formation. The Agbada formation is overlain by the Benin Formation being the youngest formation. This is based on the works of Short and Stauble (1967).

The Benin Formation covers $80 \%$ of the rocks seen on the surface in the study area. It is underlain by the paralic Agbada Formation. The sedimentary units of the Benin Formation is comprised of inter fingering units of lacustrine and fluvial loose sands, pebbles, clays, and lignite streaks of varying 


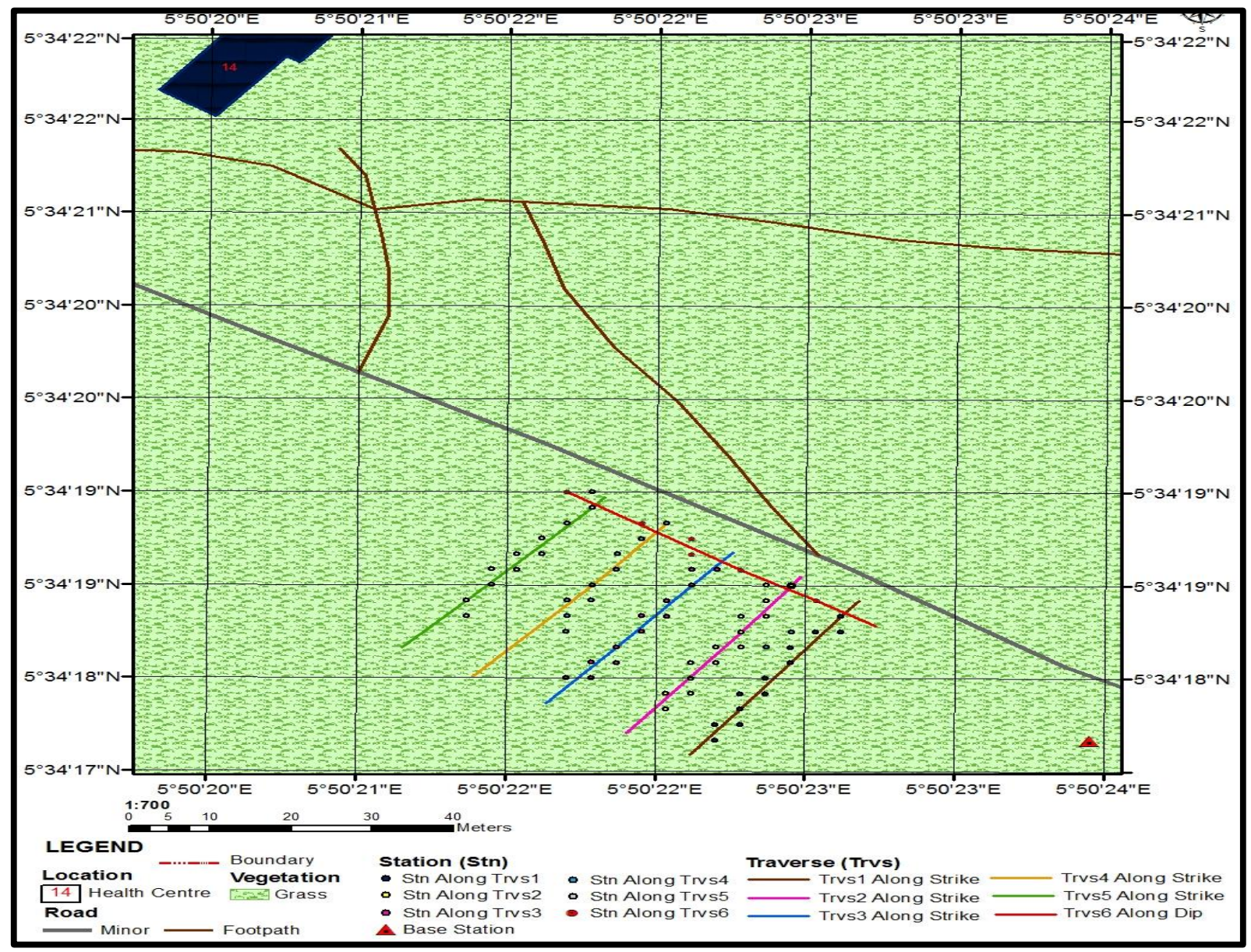

Figure 2: Base map of study area showing traverses occupied during data acquisition

thicknesses while the alluvial units is comprised of tidal and lagoon sediments and beach sands which are mostly found along the river banks.

The Agbada Formation consists of the sands intercalated by clays and shales while the Akata Formation occurs beneath comprising predominantly of shales rich in organic matter. Existing literature on the geology of the area are well documented from the exploration activities of oil and gas companies in the area Short and Stauble (1967) ${ }^{[8]}$. The Benin Formation is overlain by thin laterites overburden with varying thicknesses at some locations but is massively exposed near the shorelines ${ }^{[7]}$.

\section{Methodology}

Data collection: In this study, ground magnetic data was acquired using a high precision fluxgate magnetometer (AMC-6 high precision magnetometer) within six traverses five along the strike and one along the dip direction. The AMC-6 high-precision magnetometer has a high resolution and accuracy, and can calibrate the surrounding interfered magnetic field. It comes with a sensor whose height is about $51 \mathrm{~cm}$ and detect vertical component of the geomagnetic field $(Z)$. It has a measuring range of $10,000 \mathrm{nT}-100,000 \mathrm{nT}$ and resolution of $0.1 \mathrm{nT} \sim 1 \mathrm{Nt}$.

GPS readings and time were taken alongside the magnetic measurement for each point. Magnetic field (Normal)nT and magnetic field derivative (dZ)nT were also taken for each point. The derivative was taken at a height of $1.4 \mathrm{~m}$ at each station. The survey which comprised of one dip line and five strike lines had an inter traverse spacing of $5 \mathrm{~m}$ for the strike while spacing between two station for strike and dip were $2 \mathrm{~m}$ and $5 \mathrm{~m}$ respectively. Data were being recorded manually on a data sheet and computed into a computer for processing (reduction and correction) and interpretation.

It is imperative that factors affecting the recorded field other than those from the Earth's main field be eliminated so that they do not interface with the primary signal. This is because any ferromagnetic substance can produce an induced magnetic field in the presence of the Earth's main field and because modern magnetometers are very sensitive $(0.1 \mathrm{nT})$, 
the field crew running the magnetic survey were demagnetized of all ferrous objects.

\section{Data processing and interpretation}

In practice, the only corrections routinely carried out on the datasets is spatial variations in the Earth's main magnetic field, which would be equivalent to latitude corrections applied to gravity observations. The data was Plotted using logarithm to base two $\left(\log _{2}\right)$ (Hutchison, 1958) to show the pattern of distribution of the dataset since the normal plot doesn't show much distribution as data sets showed feeble changes in amplitude values. When data are close we check for skewness. For enhancing the data, we employed the upward continuation method while acquiring the data by taking the derivative $(\mathrm{dZ})$ at $1.4 \mathrm{~m}$ above the normal $(\mathrm{Z})$. We also used the gridding method to filter the data with the aid of sufer-12 program. Data interpretation was done with the identification of magnetic anomalies beneath the earth's surface in other to delineate the subsurface geology of the study area.

\section{Findings and discussion Findings: Discussion of Findings}

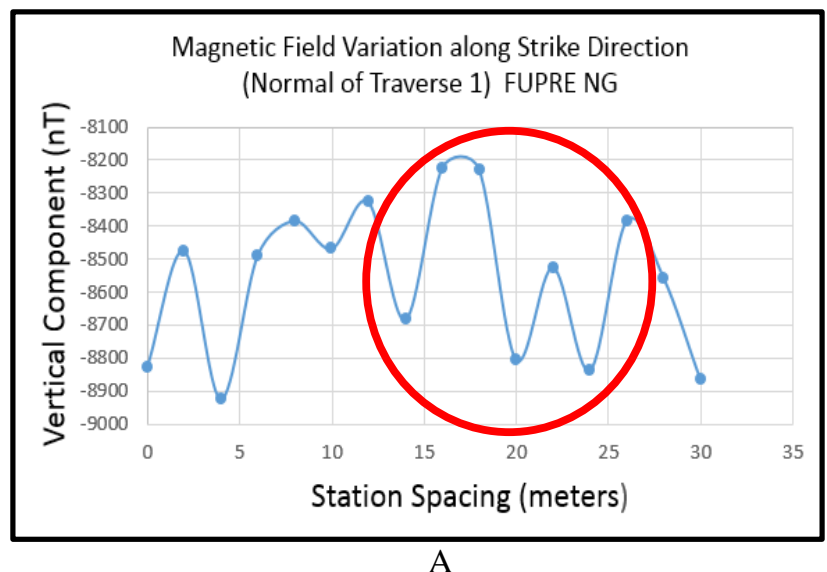

Figure 3: Magnetic Field Variation along Strike Direction (a) (Normal of Traverse 1) (b) (Normal of Traverse 1- LOG-LOG plot in base 2) FUPRE, South-South Nigeria. Figure (5b),

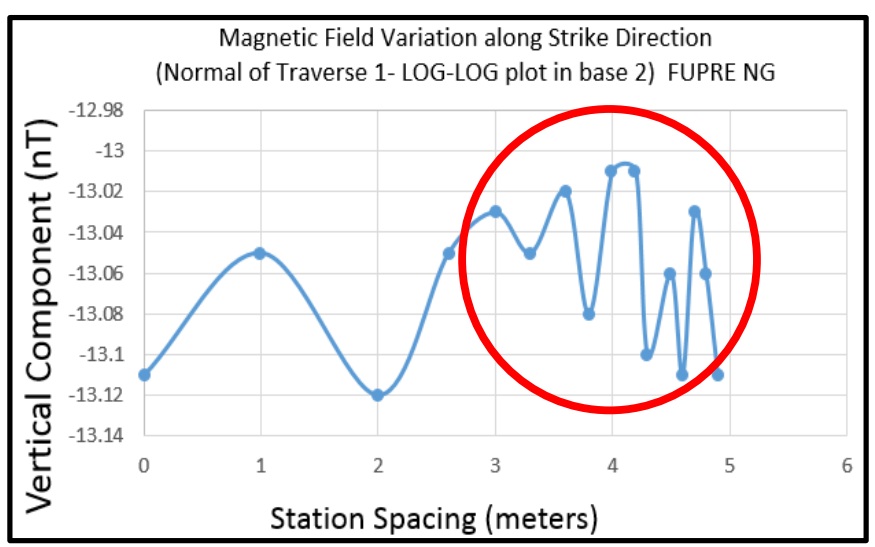

plotted in log base two (binary logarithm) was used to show skewness of the magnetic data since the amplitude values showed feeble changes i:e having a closed data set. It is used to show the distribution of the dataset, the ringed (red) part shows maximum concentration of the data.
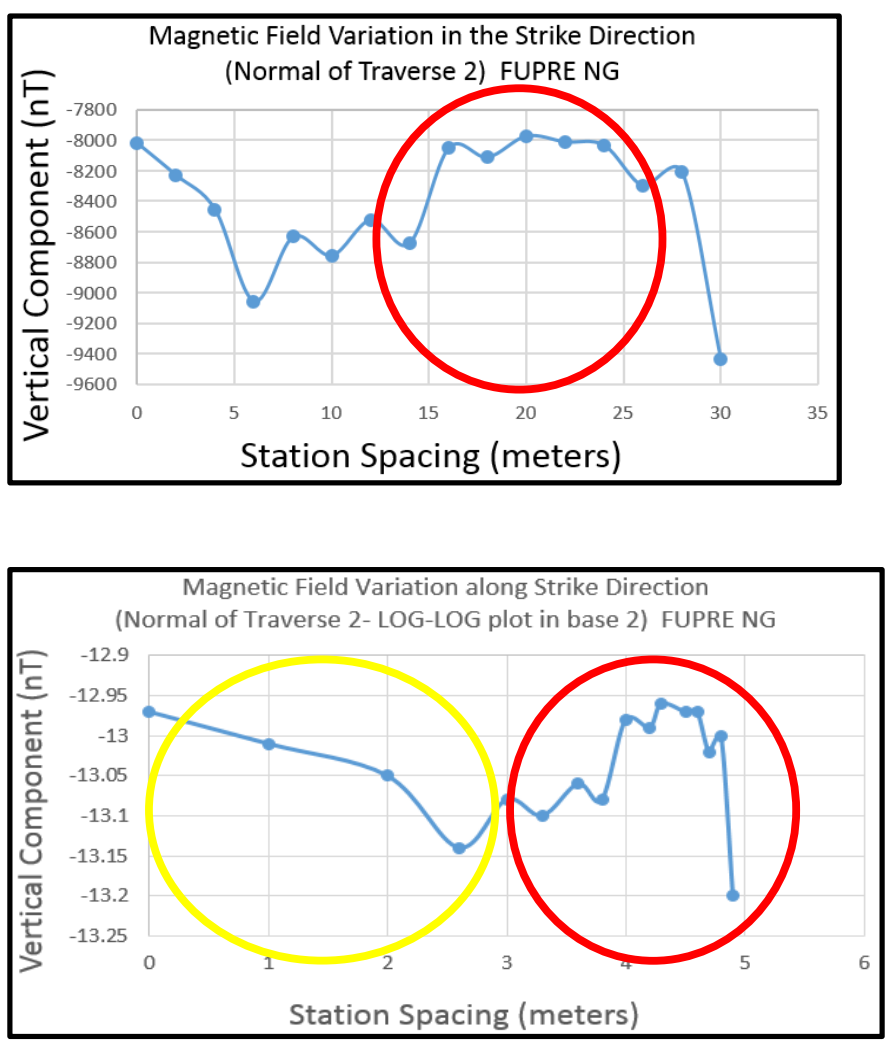

Figure 4: Magnetic Field Variation along Strike Direction (a) (Normal of Traverse 2) (b) (Normal of Traverse 2- LOG-LOG plot in base 2) FUPRE, South-South Nigeria.

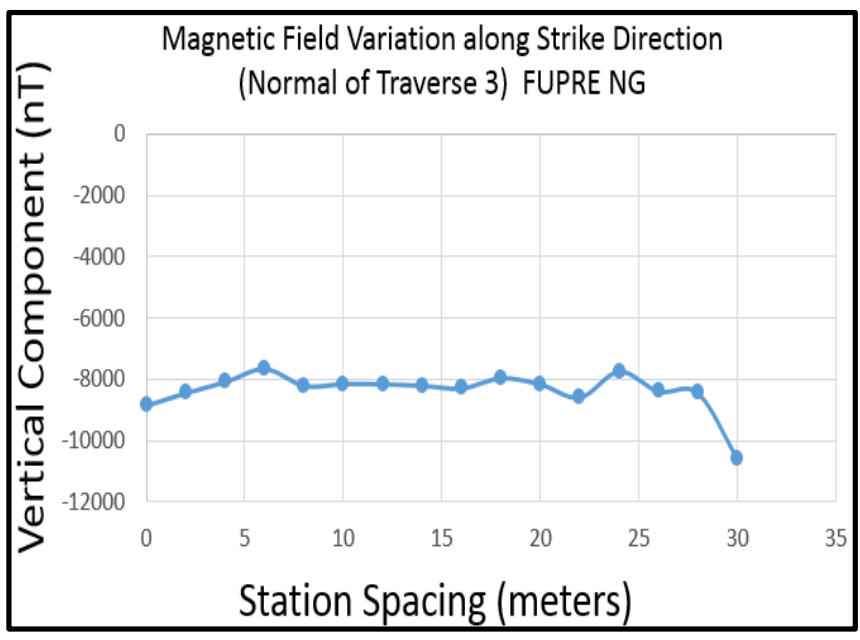




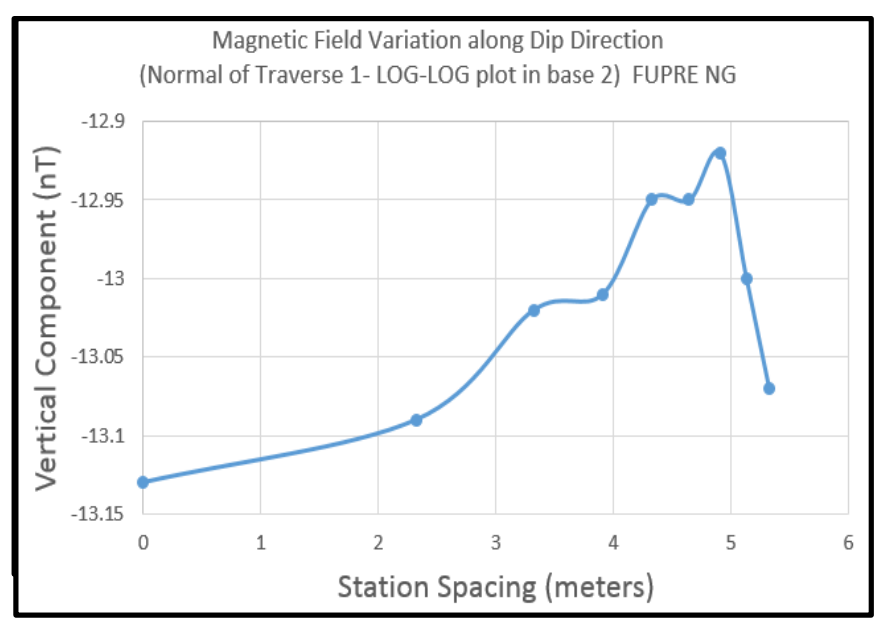

Figure 5: Magnetic Field Variation along Strike Direction (a) (Normal of Traverse 3) (b) (Normal of Traverse 3- LOG-LOG plot in base 2) FUPRE, South-South, Nigeria.

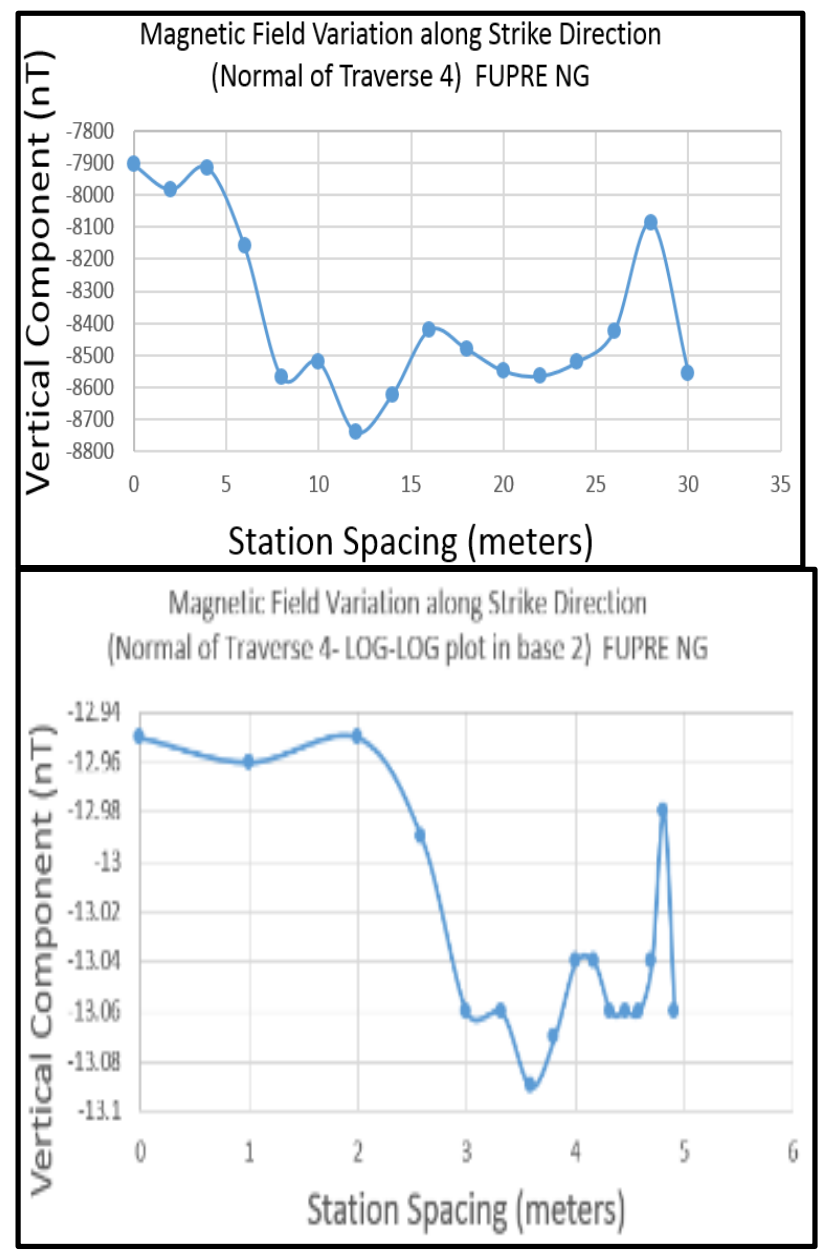

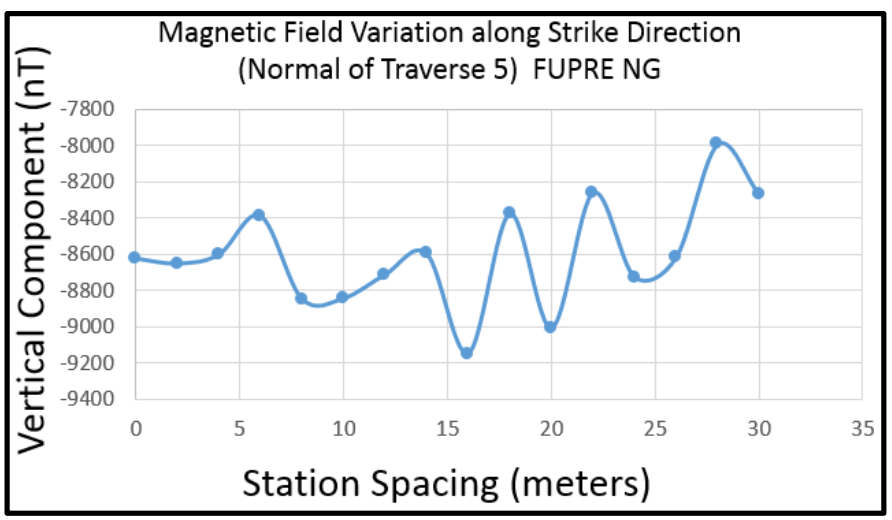

Magnetic Field Variation along Strike Direction (Normal of Traverse 5- LOG-LOG plot in base 2) FUPRE NG

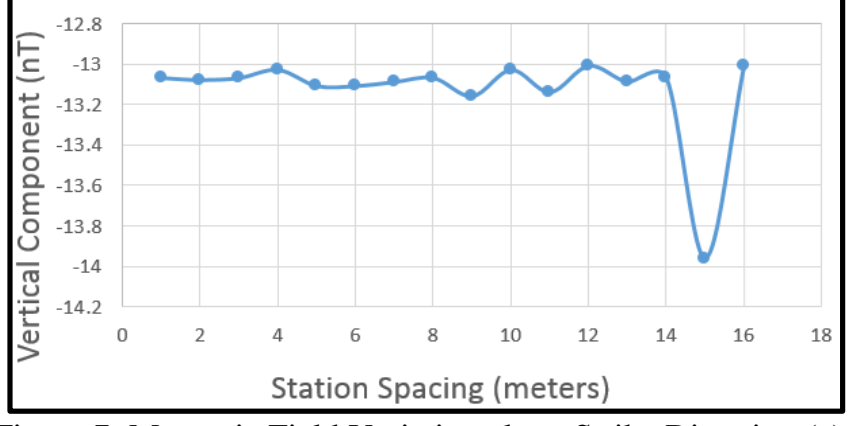

Figure 7: Magnetic Field Variation along Strike Direction (a) (Normal of Traverse 5) (b) (Normal of Traverse 3- LOG-LOG plot in base 2) FUPRE, South-South, Nigeria.

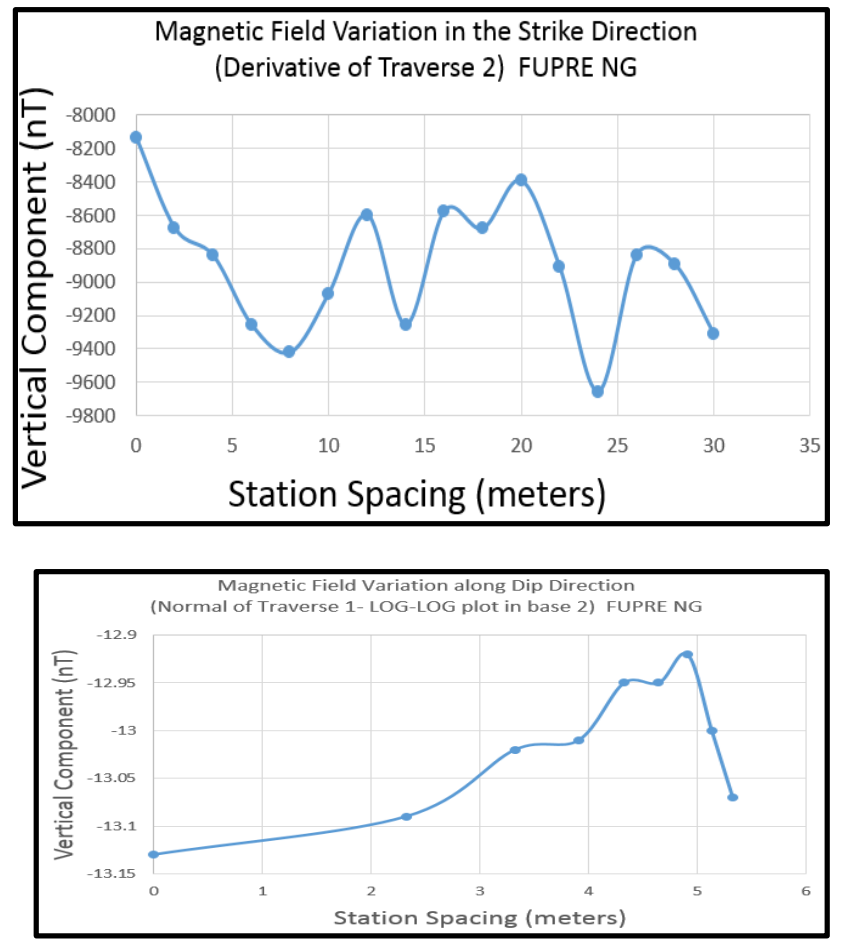




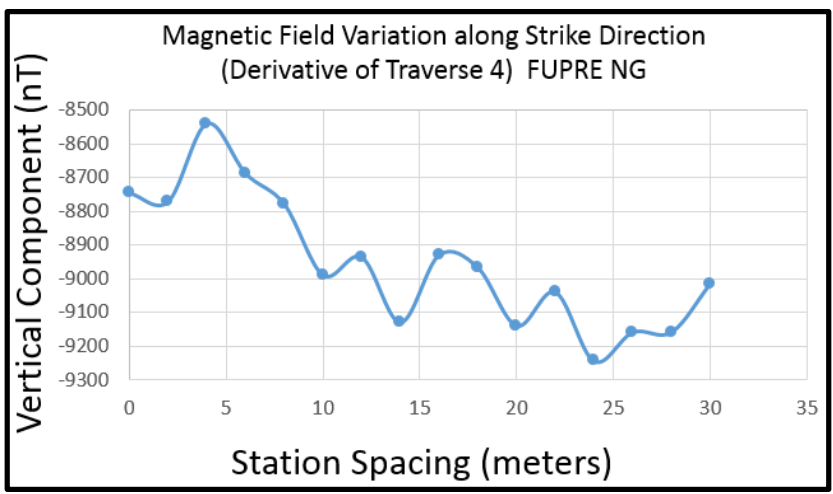

Figure 8: Magnetic Field Variation along Dip Direction (a) (Normal of Traverse 1) (b) (Normal of Traverse 1- LOG-LOG plot in base 2) FUPRE, South-South Nigeria.

A comparism was made between Magnetic Field derivative (dZ) of traverses $1-5$ taken at $1.4 \mathrm{~m}$ above the normal vertical field (z) along Strike Direction and binary logarithm (LOGLOG plot in base 2) of derivative (dZ) along Strike direction for traverses 1-5 FUPRE, South-South Nigeria.

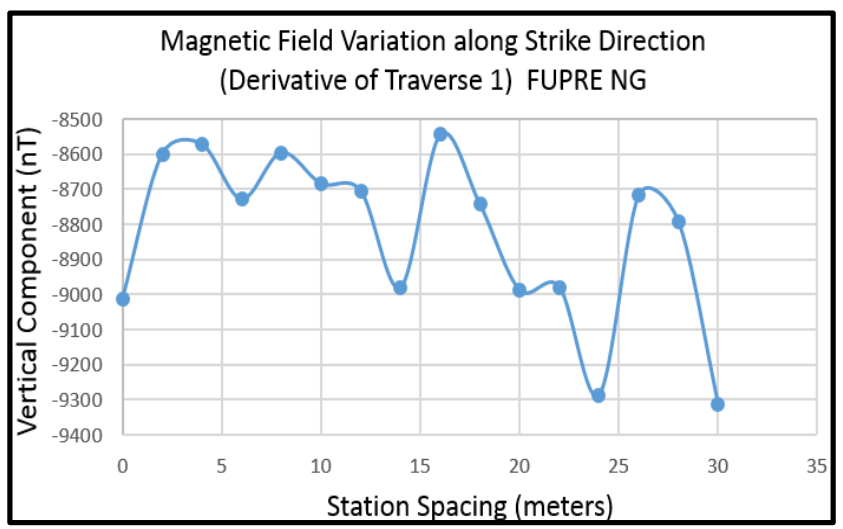

Magnetic Field Variation along Strike Direction

(Derivative of Traverse 1- LOG-LOG plot in base 2) FUPRE NG

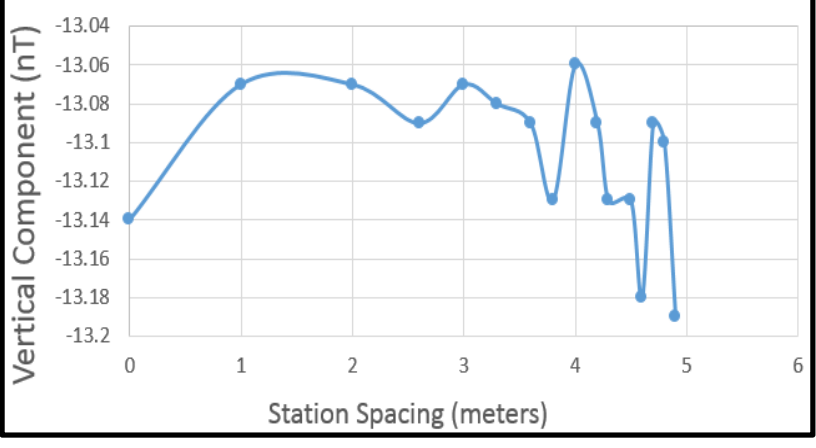

Figure 9: Magnetic Field Variation along Strike Direction (a) (Derivative of Traverse 1) (b) (Derivative of Traverse 1LOG-LOG plot in base 2) FUPRE, South-South Nigeria.

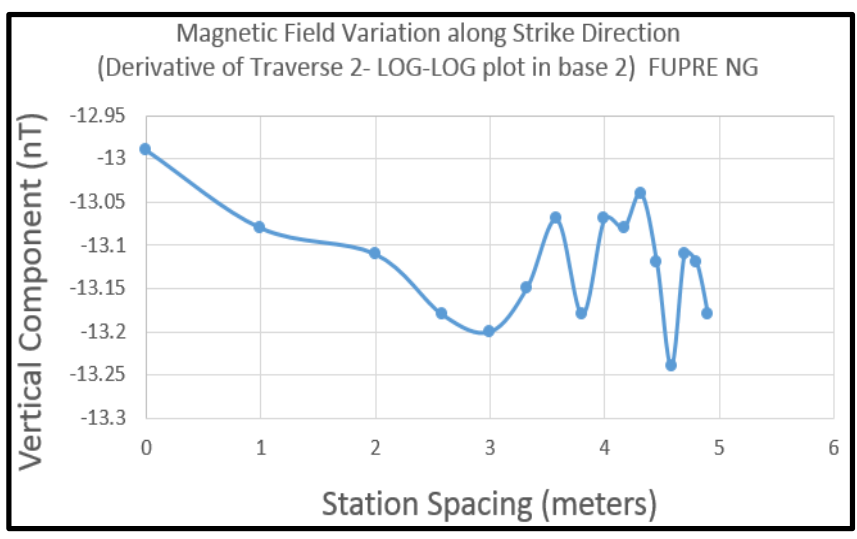

Figure 10: Magnetic Field Variation along Strike Direction (a) (Derivative of Traverse 2) (b) (Derivative of Traverse 2 LOG-LOG plot in base 2) FUPRE, South-South Nigeria.

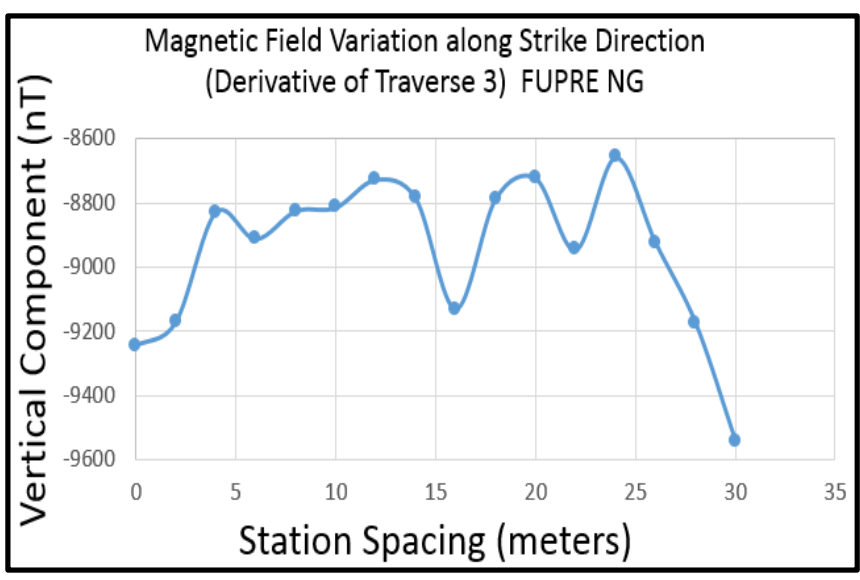

Figure 11: Magnetic Field Variation along Strike Direction (a) (Derivative of Traverse 3) (b) (Derivative of Traverse 3LOG-LOG plot in base 2) FUPRE, South-South Nigeria.

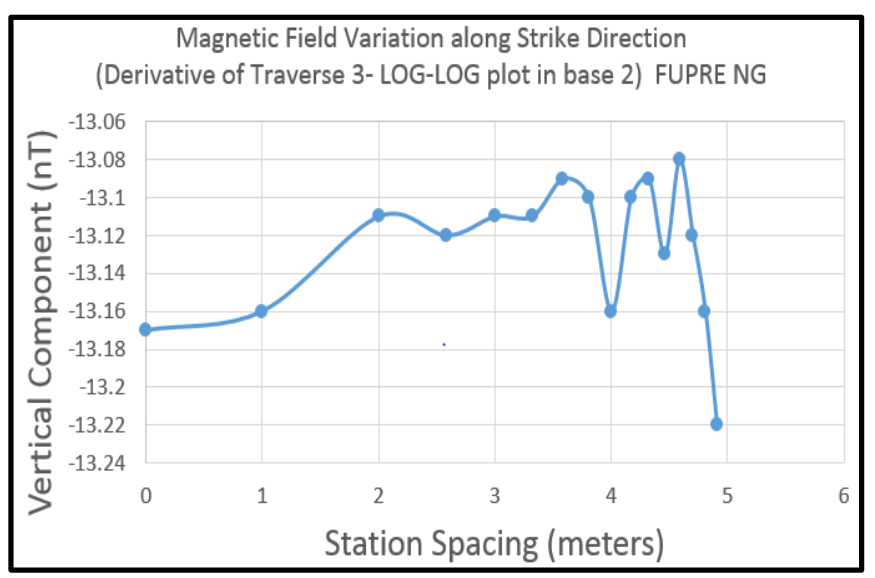

Figure 12: Magnetic Field Variation along Strike Direction 


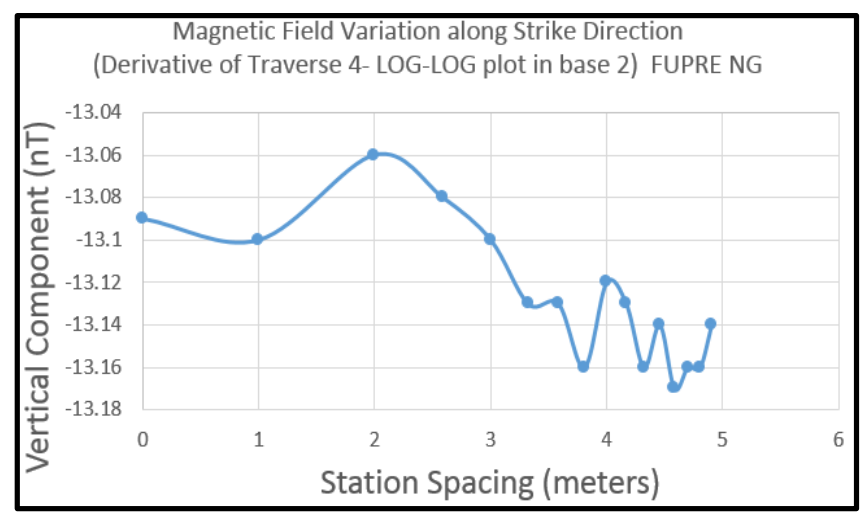

(a) (Derivative of Traverse 4) (b) (Derivative of Traverse 4LOG-LOG plot in base 2) FUPRE, South-South Nigeria.

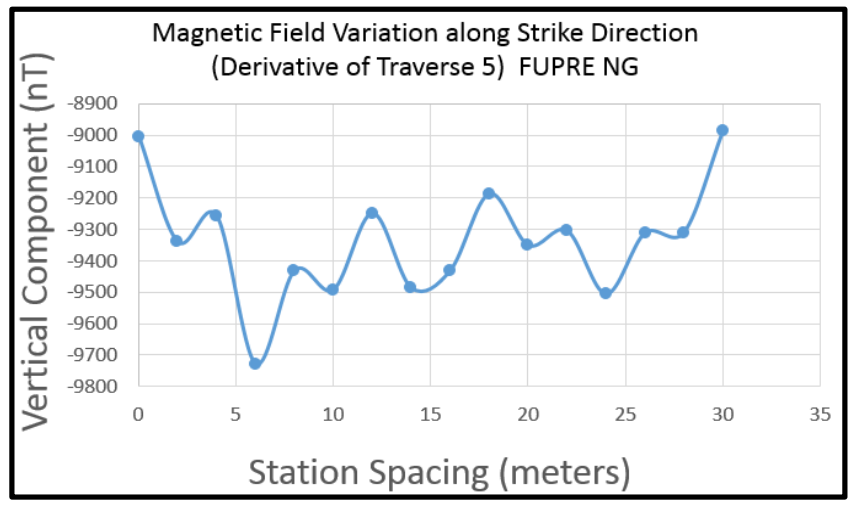

Comparison between magnetic Field Variation along Strike direction (for normal and derivative of normal (dZ)) for traverses 1-5 FUPRE NG and their corresponding LOG-LOG

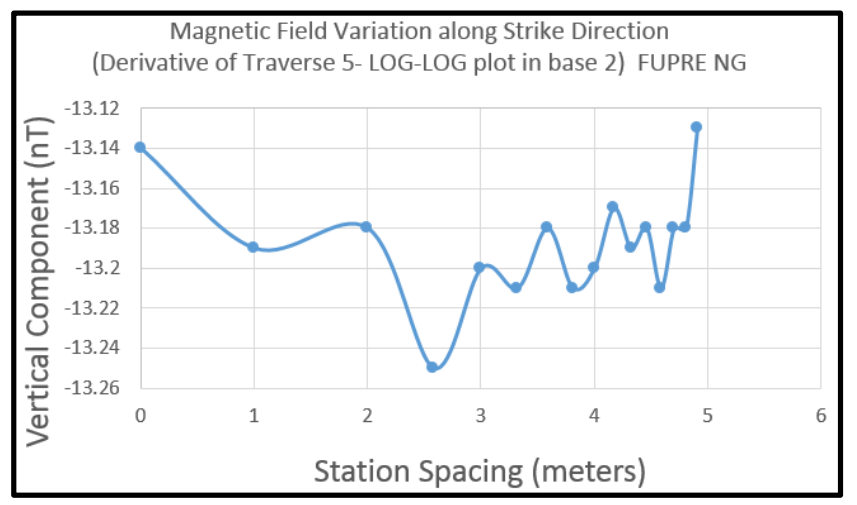

plots in base 2, indicates that plotting with log base two tends to check for skewness in the dataset. The logarithmic plots shows best how the data is distributed or where the magnetic amplitude is concentrated. Figures 3 and 4, goes further to tell us that there are two segments of the data, which are (red-
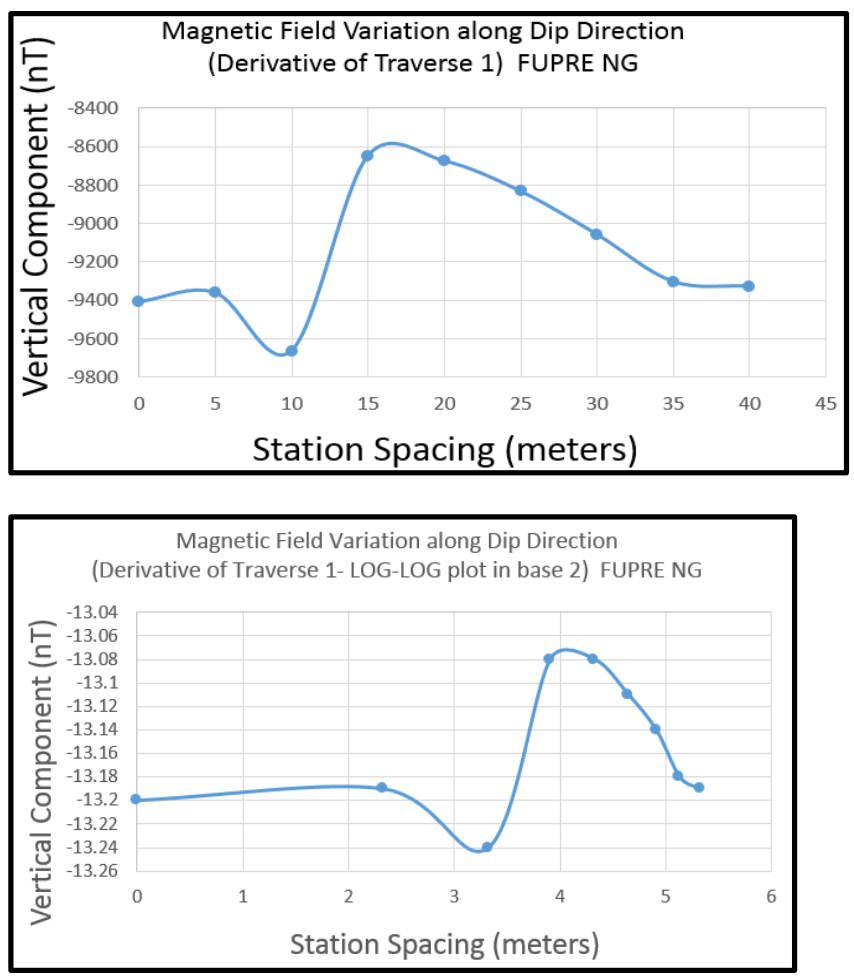

Figure 14: Magnetic Field Variation along Dip Direction (a) (Derivative of Traverse 1) (b) (Derivative of Traverse 1-

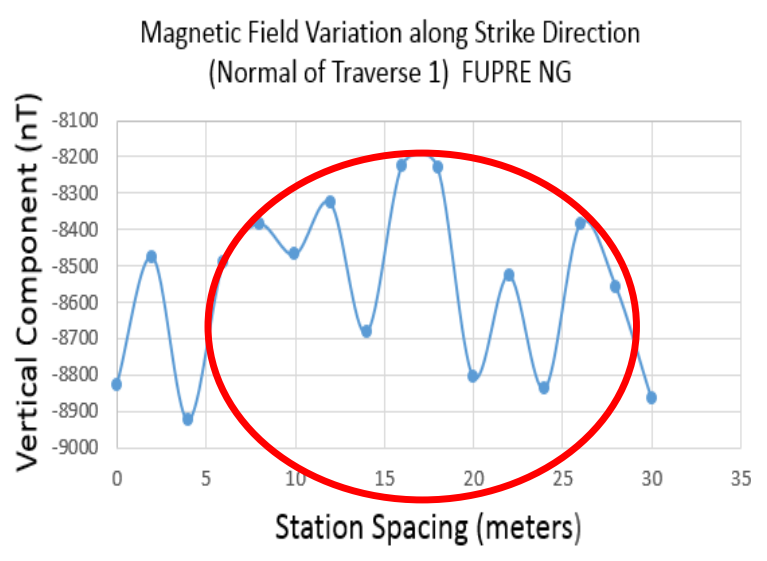

LOG-LOG plot in base 2) FUPRE, South-South Nigeria.

Figure 15: Diagram showing Comparism between magnetic field variation along strike direction traverse 1 (a) Normal (z) of traverse 1 (b) Derivative (dZ) of traverse 1 (c) corrected normal (z) of traverse 1. A slight change is observe between (a) and (c), this shows there is little error in the normal (z) magnetic data acquired along traverse 1 . 
Magnetic Field Variation along Strike Direction (Derivative of Traverse 1) FUPRE NG

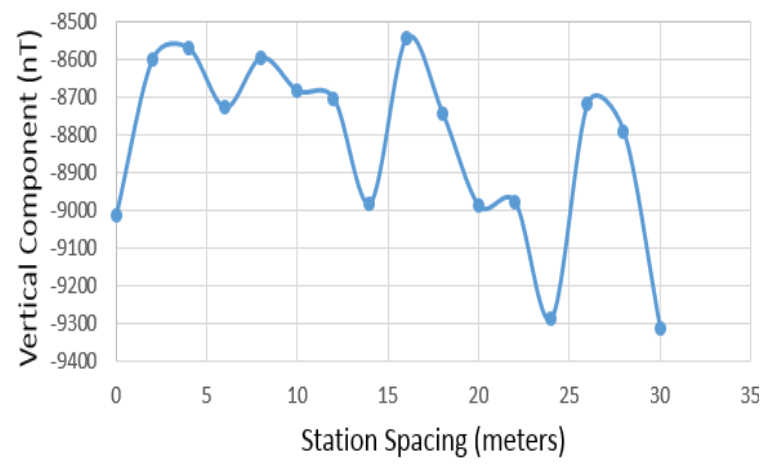

Magnetic Field Variation along Strike Direction (CORRECTED Normal of Traverse 1) FUPRE NG

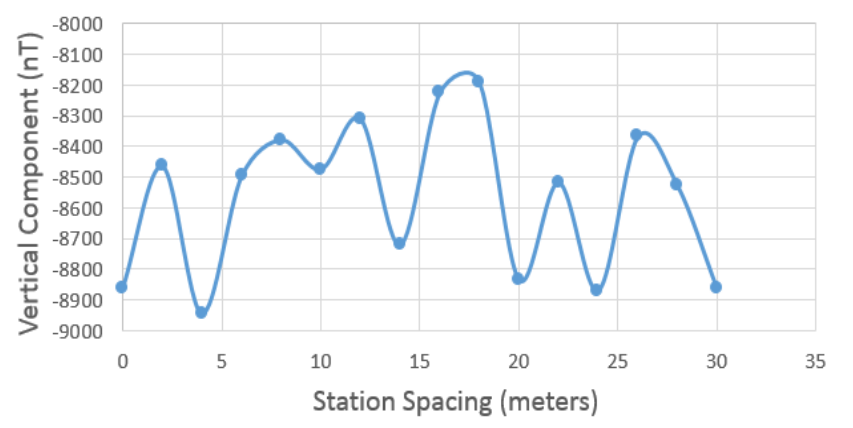

circled) segment where there is concentration of the data which depicts areas having similar magnetic properties while (yellow-circled) shows a dispersion in the dataset. When magnetic data are close in their amplitude values we check for skewness (change or trend in a particular direction) unlike resistivity data whose dataset is often made up of high and Figure 13: Magnetic Field Variation along Strike Direction (a) (Derivative of Traverse 5) (b) (Derivative of Traverse 5LOG-LOG plot in base 2) FUPRE, South-South Nigeria.

\section{References}

[1]. Hutchison, R. D. (1958). Magnetic analysis by logarithmic curves. Geophysics, Vol(23), No. 4, Doi:10.1190/1.1438525, p.749-769.

[2]. Meteorological and Climate Report of Effurun between 1999-2015, http://homepage.ufp/Wiki/climate.page10.html.

[3]. Nicolas, O.M. (2008). The Magnetic method. In Exploration for Geothermal. Lake Naivasha, Kenya.

[4]. Odemerho, F.O., and Ejemejovwi, D.O. (2007). The physiographic provinces and drainage systems of Delta State, Nigeria. low values. A close observation at the plots (figures 3, 4, 5, 6, ... 15), notice that at regions of concentration of data we have a peak (highest point). Figure 16a is the map of the vertical component (ZnT) for traverses 1-5 in the area which shows the geology of the area, but due to its noisy nature, it does not depict the true subsurface geology of the area. In figure 16b, which is the map of derivative of the vertical component $(\mathrm{dZnT})$ taken at $1.4 \mathrm{~m}$ above the normal field which is an enhancement of the vertical component (ZnT), it depicts the subsurface geology of the study area i:e the derivative helped to sharpen the dataset. The ringed area (in red) which is the North-Eastern part of the map, shows a steep slope (closely spaced contours) while the central ringed area (in blue) has an anticlinal structure which are decreasing gentle outwardly. Finally, there is a gentle slope which decrease towards the Western part of the map.

\section{Conclusions}

This Study have presented a quanlitative and semi quantitative interpretation of magnetic data acquired in some parts of the Federal University of Petroleum Resources, Effurun. The quantitative interpretation involves the plotting of the vertical component against station spacing. The use of the logarithmic curve to base two helped in interpretation of the data to check for skewness in data distribution. The magnetic susceptibility of the area is low because magnetism experienced in the area are from either diamagnetic or paramagnetic causative sources.

The dataset was enhanced by taking the derivative reading using the upward continuation technique, and carrying out data correction procedures by filtering the data to remove noise and normalization to remove errors. Upon filtration and normalization of data, little or no errors were found indicating that the dataset was acquired properly. The results obtained indicated the presence of anticlinal structures in the subsurface which have valley-like depressions between them.

[5]. Okeke, C.J., Ukaegbu, V.U. and Egesi, N. (2019). Remote sensing signature of geological structures inferred on landsat imagery of Afikpo area Southeastern Nigeria. Journal of Geology

[6]. and Mining Research, Vol. 11(1) Doi: 10.5897/JGMR2018.0305 p.1-13.

[7]. Opara, A.I., Emberga, T.T., Oparaku, O.I., Essien, A.G., Onyewuchi, R.A., Echetama, H.N., Muze, N.E., and Onwe, R.M. (2015). "Magnetic Basement Depth Re-Evaluation of Naraguta and Environs North Central Nigeria, Using 3-D Euler Deconvolution." American Journal of Mining and Metallurgy, Vol. 3, No. 2, Doi: 10.12691/ajmm-32-1, p.29-42.

[8]. Short, K.C., Stauble, A.J. (1967). Outline of geology of Niger Delta. AAPG Bulletin. 51(5): p.761 - 779 . 